Ann. Biol. anim. Bioch. Biophys., 1979, 19 (1A), 55-71.

\title{
Variations des teneurs sanguines en acides aminés libres, urée et glucose chez la brebis en fin de gestation et début de lactation. Influence de l'état nutritionnel en fin de gestation
}

\author{
par J. GRIZARD, M. TISSIER *, C. CHAMPREDON, J. PRUGNAUD, R. PION \\ avec la collaboration technique de G. BAYLE, O. BERNARD, E. DEBRAS, A. BRELURUT*, \\ J. LEROUX * \\ Laboratoire d'Etude du Métabolisme azoté \\ * Laboratoire de la Production ovine \\ I.N.R.A., Theix, Saint Genès Champanelle, 63110 Beaumont.
}

Summary. Glucose, urea, amino acids in the blood of ewes during pregnancy and lactation. Effect of nutritional state during late pregnancy.

A factorial experiment using 28 Limousine ewes (table 1) was carried out to study protein metabolism during pregnancy and lactation. The experimental treatments included two levels of energy intake during 7 weeks prepartum (high : $\mathrm{H}$; low : B) (table 2) and two states of body reserves at 8 weeks prepartum (fat : $G$; lean : $M$ ). The animals bore or were suckling either twins (D) or singles (S). Preprandial and postprandial jugular blood samples were taken at 38, 24 and 10 days prepartum and at 5, 13, 26 and 40 days postpartum. Blood glucose, urea and free amino acids were recorded.

During pregnancy. Reducing dietary energy supply resulted in a large decrease of lamb birthweight $(-0.8 \mathrm{~kg})$ and a diminution of the levels of glucose (fig. 1), some non-essential (alanine, citrulline) and some essential (tyrosine, phenylalanine, threonine, valine, leucine) free amino acids (fig. 3) in the blood of ewes ; blood urea increased (fig. 2). Reducing body reserves caused a small drop in lamb birthweight $(-0.3 \mathrm{~kg})$ and an increment of glucose (fig. 1) and free methionine (fig. 3) in the blood. During the last 2 weeks of pregnancy, postprandial blood glucose level rose (fig. 1).

During lacfation. During the first 2 weeks of lactation, the amino acid requirements for milk protein synthesis were higher than amino acid supply by the digestive tract (fig. 5). At 1 week postpartum, ewes showed very high blood leveis of most ot the essential free amino acids, free proline and free glycine (fig. 4). Some of the essential free amino acids (valine. leucine, phenylalanine, lysine, histidine) then decreased. Reducing body reserves resulted in an increment of most of the essential free amino acids in the blood. Blood levels of some of these amino acids seemed to be related to blood free methionine (table 5). Reducing the energy supply of the diet during late pregnancy increased blood glucose (fig. 1).

\section{Introduction.}

La fin de la gestation est une période critique du cycle reproductif des brebis, particulièrement dans le cas de portées multiples. Elle se caractérise par un déficit important dans les apports d'énergie par l'alimentation. En effet, la captation du 
glucose par l'utérus est fortement accrue (Kronfeld, 1972) par la croissance pondérale très importante des fœtus, alors que les apporis sont ralentis par la diminution de la consommation volontaire (Tissier, Thériez et Molénat, 1975). Celle-ci est due à l'accroissement du volume de l'utérus ; elle peut aussi résulter de la baisse de la sécrétion de progestérone (Bassett et al., 1969) et de l'augmentation de celle des œstrogènes (Terqui et Delouis, 1975) qui respectivement favorisent et inhibent l'ingestion (Baile et Forbes, 1974 ; Bargeloh, Hibbs et Conrad, 1975). La captation de matières azotées par l'utérus gravide ne dépasse les apports alimentaires que pendant les quelques jours précédant la mise bas (Tissier et Thériez, 1978). Ces carences se traduisent par une diminution des proportions de glucose et d'acides aminés sanguins qui sont oxydés en gaz carbonique (Ford et Reilly, 1970) et des modifications des teneurs sanguines en acides aminés libres (Offer et al., 1975). De même, pendant les deux premières semaines de la lactation, l'exportation de matières azotées et d'énergie dans le lait est très élevée ef les animaux ne peuvent l'assurer qu'au prix d'une mobilisation de leurs réserves (Broster, 1973 ; Tissier et Thériez, 1978).

Au cours de ces deux périodes, la restriction énergétique peut entraîner une utilisation accrue des acides aminés à des fins énergétiques chez les ruminants (Champredon, Rémond et Pion, 1977) comme chez les monogastriques (Rérat et Desmoulin, 1970 ; Arnal, Fauconneau ef Pech, 1972 ; Grizard ef al., 1975). Pour préciser ces phénomènes, nous avons éłudié l'influence d'une restriction énergétique pendant la fin de la gestation sur les teneurs sanguines en glucose, urée et acides aminés libres de brebis gestantes puis allaitantes suivant l'état des réserves corporelles (" gras" ou « maigre ») au début du dernier tiers de la gestation. Les concentrations sanguines de ces métabolites permettent d'estimer indirectement l'état de nutrition des ruminants ef le taux de satisfaction de leurs besoins en acides aminés (Champredon, 1972) ; les concentrations en acides aminés libres sont le reflet de la différence entre les

TABLEAU 1

Schémo expérimental

\begin{tabular}{|c|c|c|c|c|}
\hline \multirow[b]{2}{*}{ Lot } & \multirow{2}{*}{$\begin{array}{l}\text { Nbre } \\
\text { de } \\
\text { brebis }\end{array}$} & \multirow{2}{*}{$\begin{array}{l}\text { Période de constitution des lots } \\
17^{\mathrm{e}} \text { d̀ } 8^{\mathrm{e}} \text { semaine preparfum }\end{array}$} & \multicolumn{2}{|c|}{ Période de prélèvements } \\
\hline & & & $\begin{array}{l}7 \text { dernières semaines } \\
\text { de la gestation }\end{array}$ & $\begin{array}{l}6 \text { premières semaines } \\
\text { de la lactation }\end{array}$ \\
\hline $\begin{array}{l}\text { GHD } \\
\text { GBD }\end{array}$ & $\begin{array}{l}4 \\
5\end{array}$ & \multirow{2}{*}{$\begin{array}{c}\text { régime « haut » conduisant } \\
\text { à l'état « gras } »(G) \text { des } \\
\text { réserves corporelles }\end{array}$} & $\begin{array}{l}\text { haut }(\mathrm{H}) \\
\text { bas }(\mathrm{B})\end{array}$ & $\begin{array}{l}\text { allaitement de } \\
2 \text { agneaux (D) }\end{array}$ \\
\hline GHS. & 4 & & haut $(\mathrm{H})$ & $\begin{array}{l}\text { allaitement de } \\
1 \text { agneau (S) }\end{array}$ \\
\hline $\begin{array}{l}\text { MHD } \\
\text { MBD }\end{array}$ & $\begin{array}{l}4 \\
7\end{array}$ & \multirow{2}{*}{$\begin{array}{c}\text { régime « bas » conduisant } \\
\text { à l'étał « maigre » }(M) \\
\text { des réserves corporelles }\end{array}$} & régime $\left\{\begin{array}{l}\text { haut }(\mathrm{H}) \\
\text { bas }(\mathrm{B})\end{array}\right.$ & $\begin{array}{l}\text { allaitement de } \\
2 \text { agneaux (D) }\end{array}$ \\
\hline MHS & 4 & & haut $(\mathrm{H})$ & $\begin{array}{l}\text { allaitement de } \\
1 \text { agneau (S) }\end{array}$ \\
\hline
\end{tabular}


apports exogènes (alimentaires) ou endogènes (catabolisme protéique, synthèse des acides aminés non indispensables) et les diverses utilisations (synthèse des protéines des tissus et du lait, catabolisme, excrétions).

\section{Matériel et méthodes.}

1. Animaux et régimes. - L'expérience est réalisée au moyen de 28 brebis de la

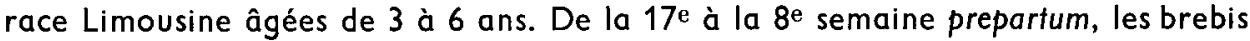
sont nourries soit de foin à volonté et de l'aliment concentré (environ $500 \mathrm{~g}$ par jour par brebis), soit de foin en quantité limitée à environ $1 \mathrm{~kg}$ par jour et par brebis (tabl. 1). Au terme de cette période préexpérimentale, les animaux sont répartis

TABLEAU 2

Comparaison des apports alimentaires et des apports estimés comme nécessaires au poids des agneaux d̀ la naissance ef aux quantités de lait produifes

\begin{tabular}{|c|c|c|c|c|c|c|c|c|c|c|c|c|c|}
\hline \multicolumn{2}{|l|}{ Lot } & \multicolumn{2}{|c|}{ GHD } & \multicolumn{2}{|c|}{ GBD } & \multicolumn{2}{|c|}{ MHD } & \multicolumn{2}{|c|}{ MBD } & \multicolumn{2}{|c|}{ GHS } & \multicolumn{2}{|c|}{ MHS } \\
\hline \multicolumn{2}{|c|}{$\begin{array}{c}\text { Poids des brebis à } \\
49 \text { jours prepartum }(\mathrm{kg})\end{array}$} & \multicolumn{2}{|c|}{68} & \multicolumn{2}{|c|}{65} & \multicolumn{2}{|c|}{74} & \multicolumn{2}{|c|}{67} & \multicolumn{2}{|c|}{62} & \multicolumn{2}{|c|}{62} \\
\hline \multirow{8}{*}{$\begin{array}{l}\text { Jours après } \\
\text { la mise-bas }\end{array}$} & & (1) & $\left.{ }^{2}\right)$ & (1) & $\left({ }^{2}\right)$ & (1) & $\left({ }^{2}\right)$ & (1) & $\left.{ }^{2}\right)$ & (1) & $\left.\left({ }^{2}\right)\right)$ & (1) & $\left({ }^{2}\right)$ \\
\hline & $\begin{array}{l}\text { MOD } \\
\text { MAD . } \\
\text { PDI . }\end{array}$ & $\begin{array}{l}904 \\
116 \\
119\end{array}$ & $\begin{array}{l}1,27 \\
1,23 \\
1,47\end{array}$ & $\begin{array}{r}623 \\
133 \\
97\end{array}$ & $\begin{array}{l}0,90 \\
1,56 \\
1,16\end{array}$ & $\begin{array}{l}913 \\
117 \\
120\end{array}$ & $\begin{array}{l}1,31 \\
1,28 \\
1,36\end{array}$ & $\begin{array}{l}644 \\
137 \\
100\end{array}$ & $\begin{array}{l}0,97 \\
1,69 \\
1,26\end{array}$ & $\begin{array}{l}817 \\
104 \\
107\end{array}$ & $\begin{array}{l}1,29 \\
1,48 \\
1,53\end{array}$ & $\begin{array}{l}815 \\
104 \\
107\end{array}$ & $\begin{array}{l}1,32 \\
1,50 \\
1,55\end{array}$ \\
\hline & $\begin{array}{l}\text { MOD } \\
\text { MAD. } \\
\text { PDI . }\end{array}$ & $\begin{array}{l}949 \\
122 \\
125\end{array}$ & $\begin{array}{l}1,09 \\
1,02 \\
1,12\end{array}$ & $\begin{array}{r}614 \\
132 \\
96\end{array}$ & $\begin{array}{l}0,75 \\
1,28 \\
0,97\end{array}$ & $\begin{array}{l}904 \\
115 \\
118\end{array}$ & $\begin{array}{l}1,07 \\
1,02 \\
1,10\end{array}$ & $\begin{array}{l}652 \\
139 \\
101\end{array}$ & $\begin{array}{l}0,83 \\
1,42 \\
1,09\end{array}$ & $\begin{array}{l}864 \\
111 \\
114\end{array}$ & $\begin{array}{l}1,21 \\
1,39 \\
1,44\end{array}$ & $\begin{array}{l}852 \\
109 \\
112\end{array}$ & $\begin{array}{l}1,23 \\
1,38 \\
1,45\end{array}$ \\
\hline & $\begin{array}{l}\text { MOD } \\
\text { MAD. } \\
\text { PDI .. }\end{array}$ & $\begin{array}{l}898 \\
114 \\
117\end{array}$ & $\begin{array}{l}0,86 \\
0,75 \\
0,84\end{array}$ & $\begin{array}{r}618 \\
133 \\
96\end{array}$ & $\begin{array}{l}0,65 \\
1,05 \\
0,81\end{array}$ & $\begin{array}{l}838 \\
105 \\
108\end{array}$ & $\begin{array}{l}0,84 \\
0,73 \\
0,82\end{array}$ & $\begin{array}{l}668 \\
143 \\
104\end{array}$ & $\begin{array}{l}0,74 \\
1,20 \\
0,94\end{array}$ & $\begin{array}{l}844 \\
108 \\
111\end{array}$ & $\begin{array}{l}1,06 \\
1,24 \\
1,23\end{array}$ & $\begin{array}{l}846 \\
108 \\
111\end{array}$ & $\begin{array}{l}1,09 \\
1,19 \\
1,27\end{array}$ \\
\hline & $\begin{array}{l}\text { MOD } \\
\text { MAD . } \\
\text { PDI . }\end{array}$ & $\begin{array}{r}1435 \\
235 \\
210\end{array}$ & $\begin{array}{l}0,93 \\
0,91 \\
0,92\end{array}$ & $\begin{array}{r}1316 \\
217 \\
193\end{array}$ & $\begin{array}{l}0,81 \\
0,79 \\
0,80\end{array}$ & $\begin{array}{r}1324 \\
220 \\
194\end{array}$ & $\begin{array}{l}0,85 \\
0,86 \\
0,85\end{array}$ & $\begin{array}{r}1208 \\
198 \\
177\end{array}$ & $\begin{array}{l}0,74 \\
0,72 \\
0,73\end{array}$ & $\begin{array}{r}1055 \\
173 \\
154\end{array}$ & $\begin{array}{l}0,93 \\
1,00 \\
0,98\end{array}$ & $\begin{array}{r}1177 \\
193 \\
172\end{array}$ & $\begin{array}{l}1,03 \\
1,11 \\
1,09\end{array}$ \\
\hline & $\begin{array}{l}\text { MOD } \\
\text { MAD. } \\
\text { PDI . }\end{array}$ & $\begin{array}{r}1499 \\
244 \\
219\end{array}$ & $\begin{array}{l}0,89 \\
0,86 \\
0,87\end{array}$ & $\begin{array}{r}1475 \\
240 \\
216\end{array}$ & $\begin{array}{l}0,87 \\
0,84 \\
0,85\end{array}$ & $\begin{array}{r}1342 \\
222 \\
197\end{array}$ & $\begin{array}{l}0,80 \\
0,78 \\
0,78\end{array}$ & $\begin{array}{r}1438 \\
235 \\
210\end{array}$ & $\begin{array}{l}0,85 \\
0,82 \\
0,83\end{array}$ & $\begin{array}{r}1246 \\
203 \\
182\end{array}$ & $\begin{array}{l}0,98 \\
1,02 \\
1,01\end{array}$ & $\begin{array}{r}1216 \\
199 \\
178\end{array}$ & $\begin{array}{l}0,96 \\
1,00 \\
0,99\end{array}$ \\
\hline & $\begin{array}{l}\text { MOD } \\
\text { MAD. } \\
\text { PDI . }\end{array}$ & $\begin{array}{r}1453 \\
233 \\
212\end{array}$ & $\begin{array}{l}1,18 \\
1,23 \\
1,24\end{array}$ & $\begin{array}{r}1364 \\
221 \\
199\end{array}$ & $\begin{array}{l}0,98 \\
0,99 \\
0,99\end{array}$ & $\begin{array}{r}1276 \\
209 \\
187\end{array}$ & $\begin{array}{l}1,04 \\
1,10 \\
1,09\end{array}$ & $\begin{array}{r}1421 \\
230 \\
208\end{array}$ & $\begin{array}{l}1,02 \\
1,03 \\
1,04\end{array}$ & $\begin{array}{r}1224 \\
196 \\
179\end{array}$ & $\begin{array}{l}1,08 \\
1,14 \\
1,14\end{array}$ & $\begin{array}{r}1168 \\
188 \\
171\end{array}$ & $\begin{array}{l}1,03 \\
1,09 \\
1,09\end{array}$ \\
\hline & $\begin{array}{l}\text { MOD } \\
\text { MAD . } \\
\text { PDI .. }\end{array}$ & $\begin{array}{r}1290 \\
201 \\
187\end{array}$ & $\begin{array}{l}1,08 \\
1,10 \\
1,12\end{array}$ & $\begin{array}{r}1151 \\
182 \\
168\end{array}$ & $\begin{array}{l}0,93 \\
0,96 \\
0,97\end{array}$ & $\begin{array}{r}1231 \\
195 \\
179\end{array}$ & $\begin{array}{l}1,03 \\
1,06 \\
1,07\end{array}$ & $\begin{array}{r}1297 \\
204 \\
189\end{array}$ & $\begin{array}{l}1,05 \\
1,07 \\
1,09\end{array}$ & $\begin{array}{r}1119 \\
175 \\
163\end{array}$ & $\begin{array}{l}1,02 \\
1,07 \\
1,09\end{array}$ & $\begin{array}{l}1075 \\
168 \\
156\end{array}$ & $\begin{array}{l}0,98 \\
1,02 \\
1,04\end{array}$ \\
\hline
\end{tabular}

MOD : matière organique digestible ; MAD : matières azotées digestibles ; PDI : protéines digestibles dans l'intestin (Jarrige, Journet et Vérité, 1978).

( $\left.{ }^{(}\right)$Apport journalier $(\mathrm{g})$ déterminé dans les deux repas précédant chaque prélèvement.

(2) Rapport des apports alimentaires aux apports estimés comme nécessaires au poids des agneaux à la naissance et aux quantités de lait produites (Tissier et Thériez, 1978). 
en 2 groupes selon les états « gras » ou « maigre » des réserves corporelles, appréciés par palpation lombaire.

Pendant les 7 dernières semaines de la gestation, les apports alimentaires d'énergie sont hauts (lettre H) ou bas (lettre B) ; les apports de matières azotées sont constants. Pendant les 6 premières semaines de la lactation, les apports alimentaires d'énergie et de matières azotées sont haut ou bas selon que les animaux allaitent deux (lettre D) ou un agneau (lettre S). Les apports journaliers de matière organique digestible (MOD), de matières azotées digestibles (MAD) et de protéines digestibles dans l'intestin (PDI) (Jarrige, Journet et Vérité, 1978), précédant chaque prélèvement, sont comparés aux apports estimés comme nécessaires en fonction du poids des agneaux à la naissance ef des quantités de lait produites (Tissier et Thériez, 1978) (tabl. 2).

La répartition des animaux en 6 lots (GHD, GBD, MHD, MBD, GHS et MHS) est un schéma factoriel $2^{\mathbf{3}}$ incomplet dans lequel les 3 facteurs sont respectivement l'état des réserves corporelles ("gras»: $G$; « maigre»: $M$ ), le niveau des apports alimentaires d'énergie en fin de gestation (haut: $\mathrm{H}$; bas : B) ef le nombre d'agneaux portés puis allaités (deux : D; un : S). L'absence de lots GBS ef MBS résulte de l'imprécision sur la détermination du nombre de fœtus par radiographie aux rayons $X$ à 8 semaines prepartum (Tissier et Brelurut, 1976).

Les brebis sont logées pendant les 8 dernières semaines de la gestation et les 6 premières semaines de la lactation, en cages individuelles sur caillebotis dans des locaux éclairés de $7 \mathrm{~h}$ à $19 \mathrm{~h}$ environ et d'une température comprise entre 12 et $16^{\circ} \mathrm{C}$. Elles reçoivent 1 repas par jour distribué à $8 \mathrm{~h}$ et constitué de l'aliment concentré (à base de maïs et de tourteau d'arachide) consommé en $10 \mathrm{mn}$ environ et de foin de prairie naturelle de qualité moyenne consommé en quelques heures. La quantité de matière organique digestible (MOD), apportée sous forme de foin est deux fois plus élevée que celle qui est ingérée sous forme d'aliment concentré. Les agnelages se situent approximativement le 10 mars.

2. Prélèvements. - Des prélèvements de $10 \mathrm{ml}$ de sang jugulaire sont effectués approximativement $90 \mathrm{mn}$ après le début du repas à 39,25 et 11 jours avant la mise bas et $4,12,25$ et 39 jours après la mise bas. Des prélèvements de $50 \mathrm{ml}$ de sang jugulaire sont également effectués immédiatement avant le repas, 1 jour après la prise de sang postprandiale. Le sang esł recueilli sur héparine. Un $\mathrm{ml}$ de sang est mélangé à $5 \mathrm{ml}$ d'acide trichloracétique à $2,5 \mathrm{p}$. 100 pour le dosage du glucose ef de l'urée ; $5 \mathrm{ml}$ environ de sang sont mélangés à $35 \mathrm{ml}$ d'éthanol $95^{\circ}$ (à $-10-15^{\circ} \mathrm{C}$ ) pour le dosage des acides aminés libres.

3. Méthodes analytiques. - Le glucose et l'urée sont dosés dans les échantillons de sang déprotéinisés par l'acide trichloracétique à 2,5 p. 100 respectivement selon les méthodes à la glucose-oxydase ef la diacétyl-monoxime au moyen d'une chaîne d'analyse automatique.

Le dosage des acides aminés libres a été effectué seulement chez les animaux portant puis allaitant 2 agneaux, dans les prélèvements préprandiaux des sangs groupés par lot. Les acides aminés libres sont extraits à partir de 15 à $20 \mathrm{~g}$ de sang, par épuisements successifs à l'éthanol à 82 p. 100 contenant 2 p. 100 de thiodiglycol pour éviter l'oxydation de la méthionine. Les extraits sont purifiés sur Amberlite IR 
120 (Pawlak et Pion, 1968). Les acides aminés sont séparés et dosés sur résine échangeuse d'ions au moyen d'un analyseur automatique selon une modification de la méthode de Moore, Spackman et Stein (1958), appliquée aux liquides biologiques. Cetfe technique ne permet pas de séparer l'asparagine dé"la glutamine, ni les méthyllysine de la lysine et les résultats concernant ces composés sont calculés respectivement en glutamine et lysine.

4. Méthodes statistiques. - Les méthodes utilisées pour comparer les moyennes (analyses de variance) et étudier les liaisons entre les variables (régressions et corrélations) sont celles décrites par Snedecor et Cochran (1971).

\section{Résultats.}

\section{1. - Glycémie et urémie.}

Glycémie. - A 38 jours prepartum, la glycémie préprandiale est plus faible dans le lot GBD que dans les autres lots (fig. 1) ; ensuife, elle ne varie pas de façon importante pendant la fin de la gestation, à l'exception d'une baisse non significative dans le lot MBD. La glycémie postprandiale est plus forte à 39 jours prepartum dans les lots $H D$ que dans les lots $B D$ et dans les lots MD que dans les lots GD ; dans la plupart des lots, elle diminue légèrement entre 39 et 25 jours preparfum et augmente ensuite entre 25 et 11 jours prepartum, plus fortement dans les lots GD que dans les autres lots.

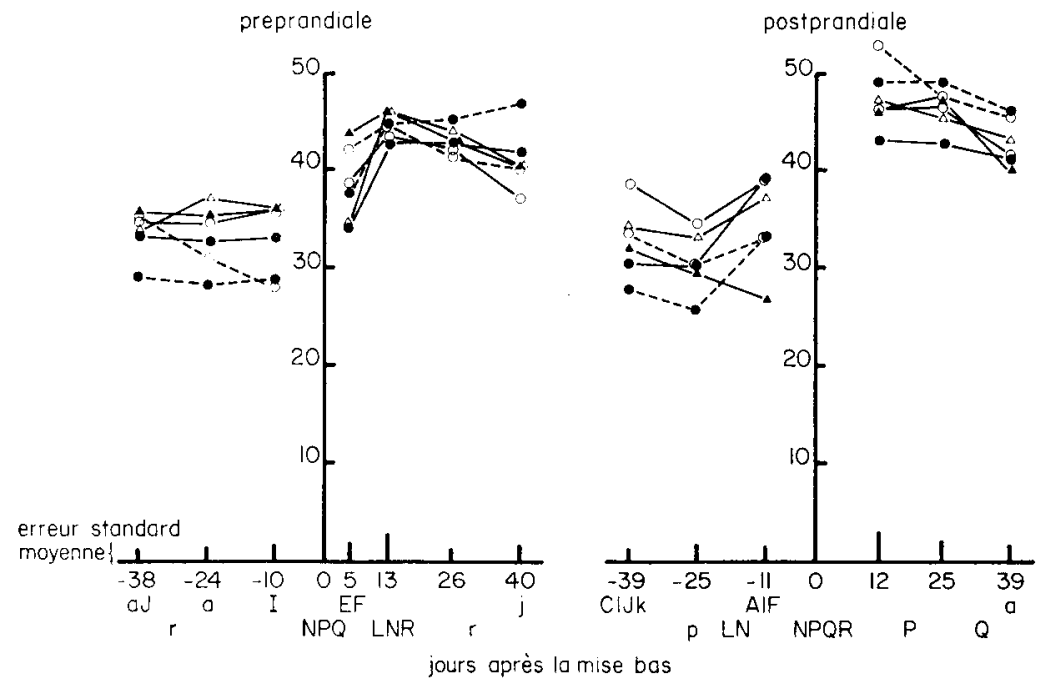

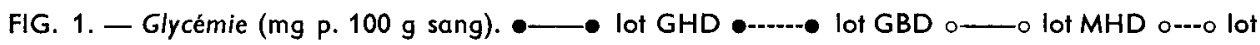
MBD $\Delta \longrightarrow \triangle$ lot GHS $\triangle-\Delta$ lot MHS. Pour chaque temps, les lettres indiquent les différences significatives entre les teneurs constatées pour les différents lots $(P \leqslant 0,050$ en lettres majuscules, $0,050<P \leqslant 0,100$ en lettres minuscules); $A$, a : lot GHD différent du lot $G B D ; 1:$ lot $M H D$ différent du lot MBD ; $C$ : GHD différent du lot MHD ; $\mathrm{j}$ : lot GBD différent du lot $M B D$; $E$ : lot GHS différent du lot MHS ; F : lot GHD différent du lot GHS ; $k$ : lot MHD différent du lot MHS. Entre deux temps consécutifs, les lettres indiquent les variations significatives des teneurs ( $P \leqslant 0,050$ en lettres majuscules, $0,050<P \leqslant 0,100$ en lettres minuscules) $L$ : dans le lot $G H D$; N dans le lot GBD;P, $p$ : dans le lot MBD; $Q$ : dans le lot GHS; $R, r$ : dans le lot $M H S$. 
Pendant le début de la lactation, les glycémies préprandiales sont égales dans les différents lots; les glycémies postprandiales sont légèrement plus fortes dans les lots BD que dans les lots HD. Les glycémies sont élevées pendant les deux premières semaines de la lactation ef diminuent ensuite sensiblement.

Urémie. - A 38 et 39 jours preparfum, les urémies préprandiales et postprandiales sont légèrement plus fortes dans les lots $B D$ que dans les lots HD (fig. 2) ; elles ne varient pas de façon notable pendant la fin de la gestation. Pendant le début de la lactation, il n'y a pas de différences significatives entre les urémies des animaux des différents lots ; celles-ci sont élevées pendant les deux premières semaines de la lactation et diminuent ensuite notablement entre les cinquième ef sixième prélèvements.

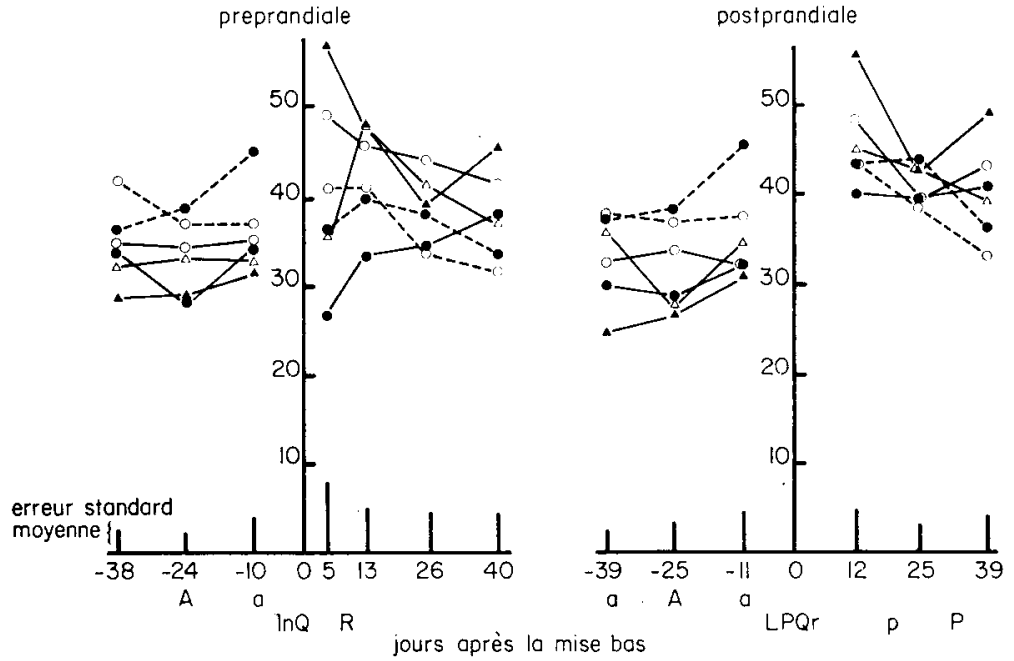

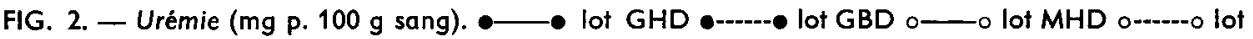
MBD $\triangle \longrightarrow$ lot GHS $\triangle-\Delta$ lot MHS. A, a : la teneur constatée pour le lot GHD est significativement différente de la valeur constatée pour le lot $G B D$ ( $P \leqslant 0,050$ en lettres majuscules $0,050<P \leqslant 0,100$ en lettres minuscules. Entre deux temps consécutifs, les lettres indiquent les variations significatives des teneurs $(P \leqslant 0,050$ en leftres majuscules, $0,050<P \leqslant 0,100$ en lettres minuscules) ; $L, I$ : dans le lot GHD ; n : dans le lot GBD ; P, p : dans le lot MBD ; $Q$ : dans le lot GHS ; R, $r$ : dans le lot MHS.

Aussi bien pour l'urémie que pour la glycémie, les teneurs postprandiales sont sensiblement égales aux teneurs préprandiales et celles-ci sont liées entre elles par une relation linéaire hautement significative (tabl. 3). Il y a aussi des relations linéaires significatives entre les urémies et les apports d'énergie et de matières azotées par l'alimentation et entre les urémies et les glycémies.

2. - Teneurs en acides aminés libres du sang.

a) Pendant la fin de la gestation.

Acides aminés non indispensables. - A 25 jours prepartum, la sous-alimentation énergétique provoque une baisse des teneurs en alanine et citrulline chez tous les 
TABLEAU 3

Comparaisons des glycémies ef urémies postprandiales respectivement aux glycémies ef urémies préprandiales (A), des glycémies aux urémies (B) et des urémies aux apports alimentaires (C)

Régressions $\mathrm{Y}=\mathrm{b} \mathrm{X}+\mathrm{K}$

\begin{tabular}{|c|c|c|c|c|c|c|}
\hline & $Y\left({ }^{1}\right)$ & $X(\mathbf{1})$ & $\mathrm{b} \pm$ écart-type & K & $\mathbf{R}^{\mathbf{2}}$ & Signification \\
\hline A & $\begin{array}{l}\text { Glycémie postprandiale } \\
\text { Urémie postprandiale }\end{array}$ & $\begin{array}{l}\text { Glycémie préprandiale } \\
\text { Urémie préprandiale }\end{array}$ & $\begin{array}{l}1,20 \pm 0,11 \\
1,04 \pm 0,11\end{array}$ & $\left|\begin{array}{l}-6,6 \\
-0,05\end{array}\right|$ & $\mid \begin{array}{l}0,78 \\
0,73\end{array}$ & $\begin{array}{l}\mathrm{P}<0,001 \\
\mathrm{P}<0,001\end{array}$ \\
\hline B & $\begin{array}{l}\text { Urémie préprandiale } \\
\text { Urémie postprandiale }\end{array}$ & $\begin{array}{l}\text { Glycémie préprandiale } \\
\text { Glycémie posłprandiale }\end{array}$ & $\begin{array}{l}0,46 \pm 0,17 \\
0,54 \pm 0,12\end{array}$ & $\begin{array}{l}20,0 \\
16,6\end{array}$ & $\begin{array}{l}0,15 \\
0,35\end{array}$ & $\begin{aligned} 0,010 & <P<0,025 \\
P & <0,001\end{aligned}$ \\
\hline & $\begin{array}{l}\text { Urémie préprandiale } \\
\text { Urémie postprandiale } \\
\text { Urémie préprandiale } \\
\text { Urémie postprandiale }\end{array}$ & $\begin{array}{l}\text { MOD }\left({ }^{2}\right) \\
\text { MOD }\left({ }^{2}\right) \\
\text { PDI }\left(^{(2)}\right. \\
\text { PDI }\left(^{(2)}\right.\end{array}$ & $\begin{aligned}-16,3 & \pm 5,5 \\
-19,6 & \pm 6,2 \\
-13,8 & \pm 4,1 \\
-18,6 & \pm 4,6\end{aligned}$ & $\begin{array}{l}53,6 \\
57,8 \\
52,5 \\
58,6\end{array}$ & $\begin{array}{l}0,18 \\
0,23 \\
0,21 \\
0,33\end{array}$ & $\begin{array}{r}0,005<\mathrm{P}<0,010 \\
0,001<\mathrm{P}<0,005 \\
0,001<\mathrm{P}<0,005 \\
\mathrm{P}<0,001\end{array}$ \\
\hline
\end{tabular}

$\mathrm{R}^{2}$ : carré du coefficient de corrélation ; $M O D$ : matière organique digestible ; PDI : protéines digestibles dans l'intestin (Jarrige, Journet et Vérité, 1978).

(1) Moyennes observées dans chaque lot à chaque prélèvement en fin de gestation et débứ de lactation.

(2) Rapport entre les apports journaliers déterminés pour les deux repas précédant chaque prélèvement ef les apports estimés comme nécessaires au poids des agneaux à la naissance et aux quantités de lait produites (Tissier et Thériez, 1978).

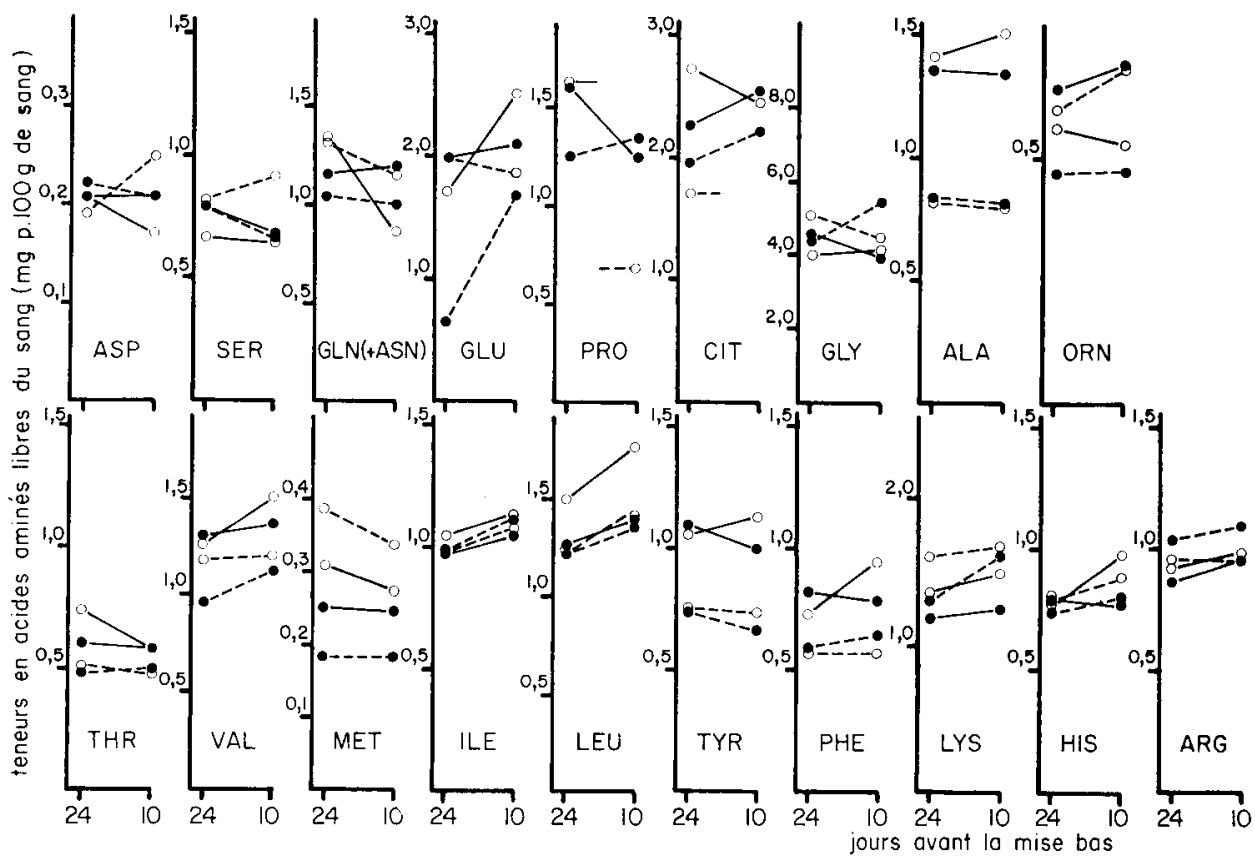

FIG. 3. - Teneurs en acides aminés libres du sang au cours de la gestation. $\bullet-\longrightarrow$ lot GHD ०—— lol MHD lot GBD o-----o lot MBD. 
animaux ainsi que des concentrations en ornithine et acide glutamique dans les lots $G$ (fig. 3). De plus, la teneur en acide glutamique est plus forte dans le lot MBD que dans le lot GBD. Ensuite, les teneurs en acide aspartique et sérine augmentent dans le lot $M B D$, ainsi que la teneur en acide glutamique dans les lots GBD ef MHD ; la teneur en glutamine + asparagine diminue dans le lot MHD.

Acides aminés indispensables et semi-indispensables. - A 25 jours prepartum, la sous-alimentation énergétique entraîne des baisses notables des teneurs en tyrosine, phénylalanine, thréonine et valine chez tous les animaux et de celle de la leucine dans les lots $M$; elle provoque également une augmentation de la teneur en arginine dans les lots $G$. Elle ne modifie que peu les parts de la thréonine et de la valine dans la somme des teneurs en acides aminés indispensables et semi-indispensables libres (tabl. 4). L'absence de réserves corporelles suffisantes se traduit par une augmen-

\section{TABLEAU 4}

Teneurs en acides aminés libres indispensables et semi-indispensables (p. 100 de leur somme) au cours de la gestation

\begin{tabular}{|c|c|c|c|c|c|c|c|c|}
\hline \multirow{2}{*}{ Jours avant la mise-bas } & \multicolumn{4}{|c|}{24} & \multicolumn{4}{|c|}{10} \\
\hline & GHD & GBD & MHD & $M B D$ & GHD & GBD & MHD & MBD \\
\hline 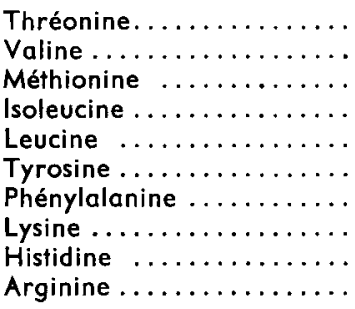 & $\begin{array}{r}6,4 \\
13,8 \\
3,2 \\
10,6 \\
13,8 \\
11,7 \\
8,5 \\
13,8 \\
8,5 \\
9,6\end{array}$ & $\begin{array}{r}6,0 \\
12,0 \\
2,4 \\
12,0 \\
14,5 \\
8,4 \\
7,2 \\
15,7 \\
9,6 \\
12,0\end{array}$ & $\begin{array}{r}7,2 \\
13,4 \\
3,1 \\
10,3 \\
15,5 \\
11,3 \\
7,2 \\
14,4 \\
8,2 \\
9,3\end{array}$ & $\begin{array}{r}5,6 \\
13,5 \\
4,5 \\
11,2 \\
13,5 \\
7,9 \\
6,7 \\
18,0 \\
9,0 \\
10,1\end{array}$ & $\begin{array}{r}6,3 \\
14,7 \\
2,1 \\
10,5 \\
14,7 \\
10,5 \\
8,4 \\
13,7 \\
8,4 \\
10,5\end{array}$ & $\begin{array}{r}5,6 \\
12,2 \\
2,2 \\
12,2 \\
15,6 \\
7,8 \\
6,7 \\
16,7 \\
8,9 \\
12,2\end{array}$ & $\begin{array}{r}5,6 \\
13,9 \\
2,8 \\
10,2 \\
16,7 \\
10,2 \\
8,3 \\
13,9 \\
9,3 \\
9,3\end{array}$ & $\begin{array}{r}5,4 \\
12,9 \\
3,2 \\
11,8 \\
14,0 \\
7,5 \\
6,4 \\
18,3 \\
9,7 \\
10,7\end{array}$ \\
\hline 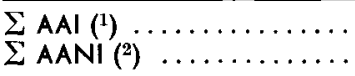 & $\begin{array}{r}9,4 \\
39,3\end{array}$ & $\begin{array}{r}8,3 \\
41,5\end{array}$ & $\begin{array}{r}9,7 \\
40,2\end{array}$ & $\begin{array}{r}8,9 \\
41,8\end{array}$ & $\begin{array}{r}9,5 \\
40,8\end{array}$ & $\begin{array}{r}9,0 \\
39,6\end{array}$ & $\begin{array}{l}10,8 \\
45,9\end{array}$ & $\begin{array}{r}9,3 \\
46,5\end{array}$ \\
\hline
\end{tabular}
de sang).

$\left.{ }^{1}\right)$ Somme des teneurs en acides aminés indispensables et semi-indispensables libres (mg p. $100 \mathrm{~g}$

( $\left.{ }^{2}\right)$ Somme des feneurs en acides aminés non indispensables libres (mg p. $100 \mathrm{~g}$ de sang).

tation des teneurs en méthionine chez tous les animaux, de celles de la valine dans les lots $\mathrm{B}$ et de la leucine dans les lots $\mathrm{H}$ (fig. 3) ; seule la part de la méthionine augmente dans la somme des teneurs en acides aminés indispensables et semi-indispensables libres dans les lots B (tabl. 4). Ensuite, les teneurs en acides aminés indispensables et semi-indispensables libres varient peu de 25 à 11 jours prepartum (fig. 3), à l'exception d'une augmentation des teneurs en phénylalanine, histidine, valine et leucine dans le lot MHD. 
TABLEAU 4 (suite)

Teneurs en acides aminés libres indispensables ef semi-indispensables (p. 100 de leur somme) au cours de la lactation

\begin{tabular}{|c|c|c|c|c|c|c|c|c|c|c|c|c|}
\hline \multirow{2}{*}{$\begin{array}{l}\text { Jours après } \\
\text { la mise-bas } \\
\text { Lots }\end{array}$} & \multicolumn{4}{|c|}{5} & \multicolumn{4}{|c|}{13} & \multicolumn{4}{|c|}{26} \\
\hline & GHD & GBD & MHD & MBD & GHD & GBD & MHD & MBD & GHD & GBD & MHD & MBD \\
\hline $\begin{array}{l}\text { Thréonine .... } \\
\text { Valine ...... } \\
\text { Méthionine ... } \\
\text { Isoleucine .... } \\
\text { Leucine ..... } \\
\text { Tyrosine .... } \\
\text { Phénylalanine } \\
\text { Lysine....... } \\
\text { Histidine ..... } \\
\text { Arginine .... }\end{array}$ & \begin{tabular}{|r|}
9,7 \\
13,6 \\
2,9 \\
9,7 \\
14,6 \\
7,8 \\
7,8 \\
18,4 \\
8,7 \\
6,8
\end{tabular} & $\begin{array}{r}8,6 \\
12,5 \\
2,9 \\
10,6 \\
14,4 \\
10,6 \\
8,6 \\
13,5 \\
10,6 \\
7,7\end{array}$ & $\begin{array}{r}13,0 \\
14,6 \\
2,4 \\
8,9 \\
15,4 \\
8,1 \\
7,3 \\
13,0 \\
11,4 \\
5,7\end{array}$ & $\begin{array}{r}8,7 \\
14,3 \\
4,0 \\
10,3 \\
13,5 \\
9,5 \\
7,1 \\
17,5 \\
9,5 \\
5,6\end{array}$ & $\begin{array}{r}10,8 \\
15,7 \\
2,4 \\
12,0 \\
18,1 \\
9,6 \\
9,6 \\
\overline{9,6} \\
12,0\end{array}$ & $\begin{array}{r}13,5 \\
13,5 \\
4,0 \\
10,8 \\
16,2 \\
13,5 \\
10,8 \\
- \\
9,5 \\
8,1\end{array}$ & $\begin{array}{r}14,7 \\
14,7 \\
3,2 \\
11,6 \\
17,9 \\
11,6 \\
8,4 \\
\overline{10,5} \\
7,4\end{array}$ & $\begin{array}{r}11,5 \\
14,9 \\
3,4 \\
11,5 \\
17,2 \\
11,5 \\
8,0 \\
\frac{11,5}{10,3}\end{array}$ & $\begin{array}{r}8,6 \\
13,5 \\
2,9 \\
9,6 \\
13,5 \\
9,6 \\
7,7 \\
14,4 \\
8,6 \\
11,5\end{array}$ & $\begin{array}{r}13,3 \\
11,1 \\
3,3 \\
10,0 \\
13,3 \\
12,2 \\
8,9 \\
12,2 \\
6,7 \\
8,9\end{array}$ & $\begin{array}{r}10,4 \\
12,5 \\
4,2 \\
9,4 \\
14,6 \\
11,5 \\
9,4 \\
11,5 \\
9,4 \\
7,3\end{array}$ & $\begin{array}{r}11,1 \\
12,2 \\
2,2 \\
10,0 \\
14,4 \\
10,0 \\
7,8 \\
15,6 \\
7,8 \\
8,9\end{array}$ \\
\hline $\begin{array}{l}\sum \text { AAI }^{(1)} \ldots \\
\sum \text { AANI }^{(2)} .\end{array}$ & $\begin{array}{l}10,3 \\
35,8\end{array}$ & $\begin{array}{l}10,4 \\
38,2\end{array}$ & $\begin{array}{l}12,3 \\
41,5\end{array}$ & $\begin{array}{l}12,6 \\
42,7\end{array}$ & $\begin{array}{r}8,3 \\
29,8\end{array}$ & $\begin{array}{r}7,4 \\
28,5\end{array}$ & $\begin{array}{r}9,5 \\
34,4\end{array}$ & $\begin{array}{r}8,7 \\
35,9\end{array}$ & $\begin{array}{l}10,4 \\
34,4\end{array}$ & $\begin{array}{r}9,0 \\
34,7\end{array}$ & $\begin{array}{r}9,6 \\
37,2\end{array}$ & $\begin{array}{r}9,0 \\
37,2\end{array}$ \\
\hline
\end{tabular}

(1) Somme des teneurs en acides aminés indispensables et semi-indispensables libres (mg p. $100 \mathrm{~g}$ de sang).

(2) Somme des teneurs en acides aminés non indispensables libres (mg p. 100 de sang).

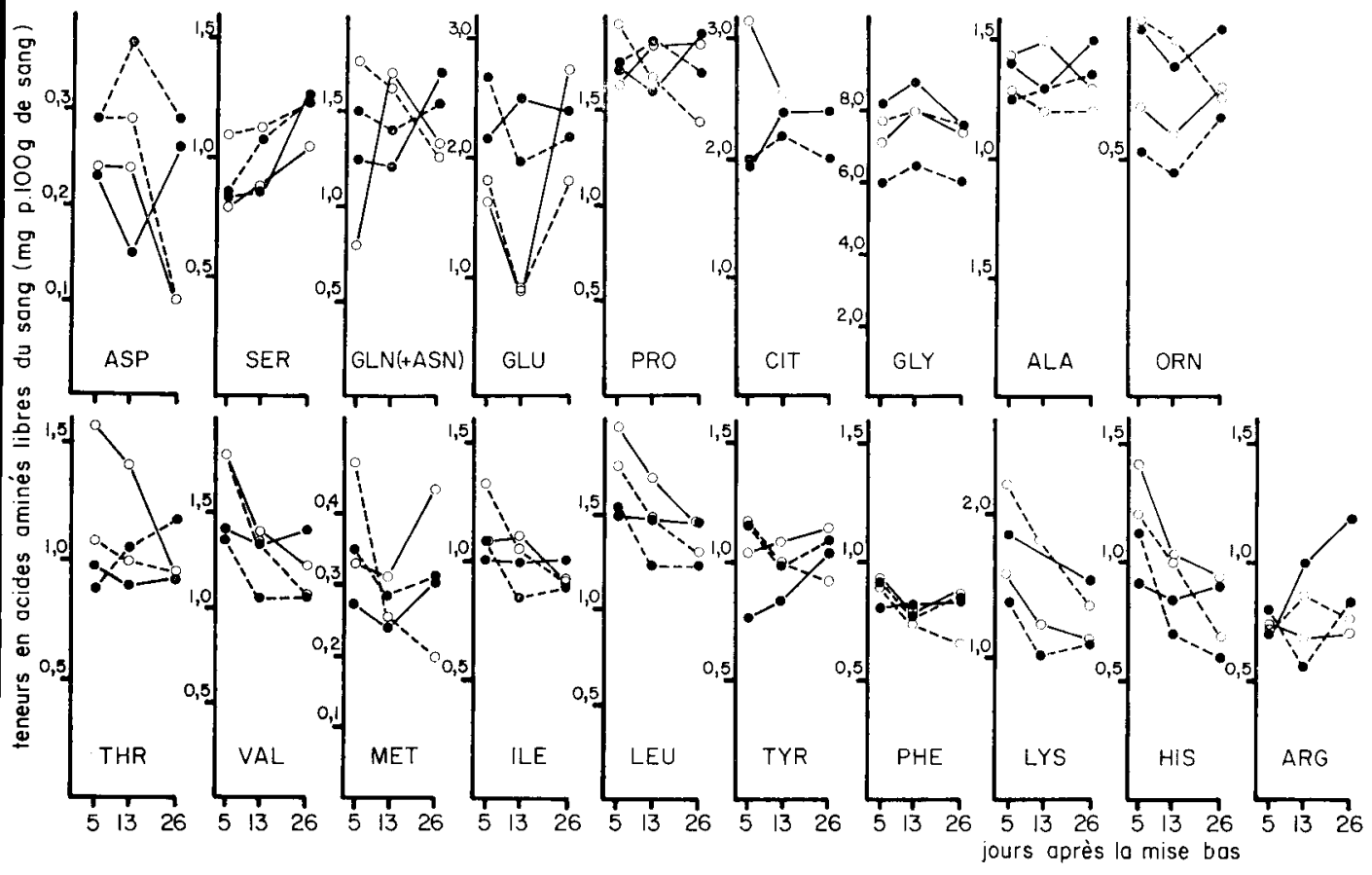

FIG. 4. - Teneurs en acides aminés libres du sang au cours de la lactation. $-\longrightarrow$ lot GHD ○—— lot MHD •-.-- lot GBD ०-.---o lot MBD. 
b) Pendant le début de la lactation.

Acides aminés non indispensables. - Chez la plupart des animaux, les teneurs en sérine, proline et glycine sont plus fortes à 4 jours postpartum qu'avant la mise bas (fig. 4). La sous-alimentation énergétique pendant la fin de la gestation se traduit alors par des accroissements des teneurs en acide aspartique et glutamine + asparagine chez tous les animaux et de celles de la sérine et de l'ornithine dans les lots $M$; les teneurs en glycine et ornithine diminuent dans les lots $G$. L'absence de réserves corporelles suffisantes provoque des réductions des teneurs en acide glutamique chez tous les animaux et de celle de l'ornithine dans les lols $\mathrm{H}$; les teneurs en glycine ef ornithine augmentent dans les lots $B$. Ensuite, les teneurs en sérine augmentent légèrement chez tous les animaux, de même que les teneurs en glutamine + asparagine dans les lots $H$; dans les lots $M$, il y a de fortes réductions des teneurs en acide glutamique à 12 jours postpartum et en acide aspartique à 25 jours postpartum.

Acides aminés indispensables et semi-indispensables. - A 4 jours postpartum dans tous les lots, les teneurs en thréonine, histidine et méthionine sont plus élevées qu'avant la mise bas, alors que les teneurs en arginine sont plus faibles. La sous-alimentation énergétique pendant la fin de la gestation se traduit alors par des augmentations des teneurs en tyrosine ef méthionine chez tous les animaux et une baisse de celle de la thréonine dans les lots $M$; la teneur en lysine augmente dans les lots $M$ et diminue dans les lots $G$. L'absence de réserves corporelles suffisantes provoque des accroissements des teneurs en leucine, valine, méthionine et histidine chez tous les animaux, tyrosine et thréonine dans les lots $\mathrm{H}$; la teneur en lysine augmente dans les lots B et diminue dans les lots $\mathrm{H}$. II n'y a que peu de modifications des parts de la valine, de

\section{TABLEAU 5}

Comparaison des teneurs sanguines en acides aminés indispensables et semi-indispensables libres (Y)

( $\mathrm{mg}$ p. $100 \mathrm{~g}$ de sang) avec les différences entre les quantités (g) de ces derniers apportées journellement par l'alimentation ef celles exportées dans le lait (X)

\begin{tabular}{|c|c|c|c|c|c|}
\hline & \multicolumn{2}{|c|}{$\begin{array}{l}\text { Régressions } \\
Y==b_{1} X+K\end{array}$} & \multicolumn{3}{|c|}{$\begin{array}{l}\quad \text { Régressions } \\
Y=b_{1} X+-b_{2} M-K\end{array}$} \\
\hline & $b_{1}$ & $\mathrm{R}^{2}$ & $b_{1}$ & $b_{2}$ & $\mathrm{R}^{2}$ \\
\hline 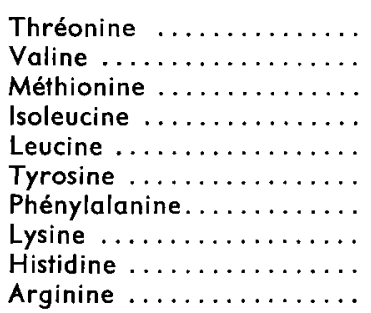 & $\begin{array}{r}-0,07 \text { (NS) } \\
-0,06 \text { (NS) } \\
-0,01 \text { (NS) } \\
-0,06\left({ }^{*}\right) \\
-0,05 \text { (NS) } \\
-0,01 \text { (NS) } \\
-0,02 \text { (NS) } \\
-0,06 \text { (NS) } \\
-0,15 \text { (NS) } \\
0,09 \text { (NS) }\end{array}$ & $\begin{array}{l}0,12 \\
0,16 \\
0,00 \\
0,36 \\
0,22 \\
0,01 \\
0,10 \\
0,11 \\
0,18 \\
0,25\end{array}$ & $\begin{array}{r}-0,21(\mathrm{NS}) \\
-0,54(\mathrm{NS}) \\
-0,30\left(^{* *}\right) \\
-0,38\left(^{*}\right) \\
-0,72\left(^{* *}\right) \\
-0,16\left(^{* *}\right) \\
-0,27(\mathrm{NS}) \\
-2,38\left(^{*}\right) \\
0,23(\mathrm{NS})\end{array}$ & $\begin{array}{c}0,26 \text { (NS) } \\
1,29(\mathrm{NS}) \\
0,48\left(^{*}\right) \\
1,10(\mathrm{NS}) \\
1,31\left(^{* *}\right) \\
0,25\left(^{*}\right) \\
0,64(\mathrm{NS}) \\
2,33 \text { (NS) } \\
-0,19 \text { (NS) }\end{array}$ & $\begin{array}{l}0,16 \\
0,32 \\
0,55 \\
0,40 \\
0,60 \\
0,40 \\
0,13 \\
0,39 \\
0,29\end{array}$ \\
\hline
\end{tabular}

$\mathrm{R}^{2}$ : carré du coefficient de corrélation ; NS : non significatif.

* : significatif au seuil de 0,$100 ; * *$ : significatif au seuil de 0,050 .

$M$ : différence entre la quantité de méthionine apportée journellement par l'alimentation et celle qui est exportée dans le lait. 
la leucine et de la tyrosine, dans la somme des teneurs en acides aminés indispensables et semi-indispensables libres (tabl. 4). Ensuite, entre 4 et 12 jours postpartum, les teneurs en valine, leucine, phénylalanine, lysine et histidine libres diminuent chez tous les animaux, à l'exception de ceux du lot GHD ; les teneurs en isoleucine, méthionine et tyrosine diminuent aussi dans les lots B (fig. 4). De 12 à 25 jours postpartum, les teneurs en acides aminés indispensables et semi-indispensables libres varient peu, à l'exception d'une forte baisse de la teneur en thréonine dans le lot MHD et des accroissements des teneurs en méthionine dans les lots $H$.

II n'y a pas de variations notables des teneurs sanguines en acides animés indispensables et semi-indispensables libres en fonction de la différence entre les quantités de chacun de ces acides aminés apportées journellement par l'alimentation et celles qui sont exportées dans le lait (tabl. 5). En revanche, dans le cas où nous avons tenu compte de l'important déficit en méthionine (covariable dans les régressions), nous avons mis en évidence une baisse significative des teneurs en isoleucine, leucine, tyrosine, phénylalanine et histidine libres à mesure qu'augmente la différence entre les quantités apportées et celles qui sont exportées. Ceci traduit le fait que l'apport des acides aminés indispensables ef semi-indispensables par le catabolisme protéique est augmenté lorsque le déficit en ceux-ci est important ; ceci souligne également le caractère limitant de la méthionine pour la synthèse des protéines du lait (Champredon, 1972).

\section{Discussion.}

\section{1. - Fin de la gestation.}

A 3 semaines prepartum, la quantité de glucose captée journellement par l'utérus (150 $\mathrm{g}$ environ dans le cas de portées doubles) (Prior et Christenson, 1977) et les tissus maternels (15 g environ), est très supérieure à celle qui est absorbée ( $35 \mathrm{~g}$ environ) (Vermorel, 1978). Les très faibles valeurs de la glycémie (30 mg p. $100 \mathrm{~g}$ de sang environ), indiquent que la néoglucogenèse à partir de l'acide propionique, de certains acides aminés, du glycérol ef des acides pyruvique ef lactique recyclés (Felig, 1973 ; Brockman et Bergman, 1975 ; Brockman et al., 1975 ; Young, 1976), ne peut compenser qu'en partie le déficit en glucose (Kronfeld, 1972).

a) Influence de la sous-alimentation énergétique pendant la fin de la gestation. La sous-alimentation énergétique entraîne une réduction importante du poids des agneaux à la naissance $(0,8 \mathrm{~kg})$ (Tissier, communication personnelle). A 3 semaines prepartum environ, elle se traduit par une diminution beaucoup plus forte de la quantité de glucose captée journellement par l'utérus ( $40 \mathrm{~g}$ environ) que de celle qui est absorbée (10 g environ) (Prior et Christenson, 1977 ; Tissier, communication personnelle ; Vermorel, 1978). En revanche, la fixation de matières azotées est diminuée dans une proportion voisine de l'apport de matières azotées par l'alimentation (tabl. 2) (Tissier et Thériez, 1978). La diminution de la glycémie traduit la baisse de la synthèse de glucose dans le foie à partir de l'acide propionique (Prior et Christenson, 1976) à la suite d'une réduction de l'activité fermentaire dans le rumen. En revanche, les réductions des teneurs sanguines en alanine et acide glutamique libres mettent en évidence un accroissement de la synthèse de glucose dans le foie à 
partir de ces composés. Les baisses des teneurs en tyrosine, phénylalanine, thréonine, valine et leucine libres résultent probablement aussi bien d'une réduction de l'apport de ces acides aminés par le tube digestif à la suite d'une diminution de la synthèse de protéines microbiennes, que d'un accroissement de leur catabolisme dans les tissus maternels; les légères augmentations des teneurs en lysine ef glycine libres sont sans doute la conséquence d'une élévation du catabolisme des protéines des tissus maternels supérieure à celle du catabolisme de ces deux acides aminés. Les augmentations de l'urémie (Guada, Robinson et Fraser, 1976), sont dues à un accroissement du fonctionnement du cycle de l'urée dans le foie, qui peut avoir deux causes : une élévation du catabolisme des acides aminés ef une réduction de l'utilisation de l'ammoniaque pour la synthèse de protéines bactériennes dans le rumen.

b) Influence de l'absence de réserves corporelles suffisantes. - L'absence de réserves corporelles suffisantes à l'approche du dernier tiers de la gestation, provoque une réduction sensible du poids des agneaux à la naissance dans les lots $D(0,3 \mathrm{~kg})$ (Tissier, communication personnelle). Ceci se traduit par une légère réduction du déficit en glucose $(13 \mathrm{~g})$ pendant les 3 dernières semaines de la gestation (Prior et Christenson, 1977 ; Vermorel, 1978) ; en revanche, le rendement de fixation de l'azote n'est pas modifié (Tissier et Thériez, 1978) (fabl. 2). Les augmentations de la glycémie sont dues à la réduction du déficit en glucose. Elles peuvent aussi s'expliquer par un accroissement de la synthèse de glucose à partir de l'acide propionique. En effet, l'activité fermentaire dans le rumen est vraisemblablement augmentée à la suite d'une moindre diminution au cours de la fin de la gestation du volume occupé par le tube digestif, associée à la réduction de la masse de graisses abdominales.

c) Influence de l'approche de la mise bas. - Entre 3 et 1 semaine environ avant la mise bas, la captation de glucose par l'utérus augmente puisque la croissance des fœtus est accrue (Tissier et Thériez, 1978) ; en revanche, l'absorption de glucose est sans doute constante puisque la quantité d'énergie ingérée n'est pas sensiblement modifiée (łabl. 2) (Vermorel, 1978). De même, la quantité de matières azotées fixées journellement dans l'utérus augmente, passant de 25 à $40 \mathrm{~g}$ environ dans les lots D (Tissier et Thériez, 1978), alors que celle qui est apportée par l'alimentation est approximativement constante et devient insuffisante (tabl. 2). Les augmentations notables de la glycémie postprandiale (Hove et Blom, 1976) ne sont pas dues à un accroissement de la synthèse de glucose à partir de l'acide propionique puisque l'activité fermentaire dans le rumen est sans doute ralentie, ni à partir des acides aminés puisque les teneurs sanguines des principaux acides aminés libres glucoformateurs (alanine, acide glutamique, sérine, glycine, acide aspartique) sont approximativement constantes ou augmentées. Elles peuvent s'expliquer par une baisse de l'utilisation du glucose par les tissus maternels (catabolisme oxydatif, lipogenèse, synthèse de glycogène). Elles peuvent être dues à l'action de la réduction de l'insulinémie (Grizard et al., 1979) et de l'augmentation de la teneur plasmatique en hormone de croissance (Koprowski et Tucker, 1973 ; Blom, Hove et Nedkvitne, 1976) puisque l'insuline et l'hormone de croissance respectivement stimulent ef inhibent l'utilisation du glucose par les tissus. Le faił que les teneurs de la plupart des acides aminés indispensables et semi-indispensables libres ne changent que peu et que les teneurs de certains d'entre eux augmentent dans le lot MHD, est probablement dû à une réduction de leur catabolisme (Ford et Reilly, 1970); il peut aussi résulter d'une réduction 
des quantités nécessaires pour l'incorporation dans les protéines des tissus maternels sous l'action de la réduction de l'insulinémie (Grizard ef al., 1979). En effet, si cette hormone accroît la synthèse des protéines (Wool, 1972), elle en ralentit aussi le catabolisme (Fulks, Li et Golberg, 1975).

\section{2. - Pendant le début de la lactation.}

a) Influence du stade de la lactation.

Première semaine. - Chez les animaux des lots $D$, la quantité de glucose utilisée journellement par la glande mammaire pour son fonctionnement ( $65 \mathrm{~g}$ environ) ef pour la synthèse du lactose ( $110 \mathrm{~g}$ environ pour $2,35 \mathrm{~kg}$ de lait) et par les tissus autres que la glande mammaire (15 g environ), dépasse considérablement celle qui est absorbée (60 g environ) (Vermorel, 1978). La glycémie plus élevée que pendant la fin de la gestation, résulte du fait que d'une part le déficit en glucose est sans doute légèrement moins intense que pendant la fin de la gestation et que d'autre part la néoglucogenèse à partir du propionate est plus forte, puisque l'ingestion est plus élevée.

Chez les animaux des lots $D$, les quantités de méthionine, histidine, tyrosine, et valine exportées journellement dans le lait, sonf supérieures ou égales aux quanfités de ces acides aminés apportées par l'alimentation; les quantités de leucine, lysine, isoleucine et arginine exportées sont légèrement inférieures aux apports (fig. 5). Les valeurs élevées des teneurs sanguines de la plupart des acides aminés indispensables et semi-indispensables libres, de même que celles de la glycine et de la proline libres, doivent donc résulter d'une forte augmentation du catabolisme protéique (utérus et trame protéique du tissu osseux), ainsi que d'une limitation de l'utilisation des acides aminés indispensables pour la synthèse des protéines du lait, due à la carence sévère en méthionine. Le fait que la teneur en thréonine libre est très élevée, comparée à celle qui est observée pendant la fin de la gestation, est dû a un apport excédentaire par rapport à la quantité captée par la glande mammaire (Spires et al., 1975) et à un catabolisme limité dans les tissus autres que la glande mammaire; le fait que la teneur en arginine est très faible, traduit une captation par la glande mammaire en quantité très supérieure à celle qui est exportée dans le lait (Bickerstaffe, Annison et Linzell, 1974). Des glycinémies et prolinémies élevées associées à des argininémies faibles ont d'ailleurs été constatées chez la vache et la chèvre fortes productrices de lait (Champredon et Pion, 1972 ; Pion, 1976 ; Champredon, Rémond et Pion, 1977) ; en revanche, des nccroissements des teneurs en acides aminés indispensables libres n'ont pas été observés chez les mêmes animaux. Les valeurs élevées de l'urémie peuvent résulter aussi bien de l'accroissement de l'activité arginasique dans la glande mammaire que de l'augmentation de l'uréogenèse dans le foie (Mackie et Campbell, 1972) ; celle-ci peut être provoquée à la fois par l'élévation du catabolisme protéique ef par ceile de l'ammoniogenèse dans le rumen, associée à l'augmentation de l'ingestion.

Deuxième semaine. - Entre la première ef la deuxième semaine de la lactation, il y a un accroissement des quantités d'acides aminés captées par la glande mammaire, non compensé par un apport suffisant d'acides aminés par l'alimentation (fig. 5). Les nettes diminutions des teneurs de la plupart des acides aminés indispensables 
libres, traduisent les accroissements de ces déficits alimentaires, aussi bien qu'une réduction du catabolisme protéique associée à l'élévation importante de l'insulinémie (Grizard et al., 1979).

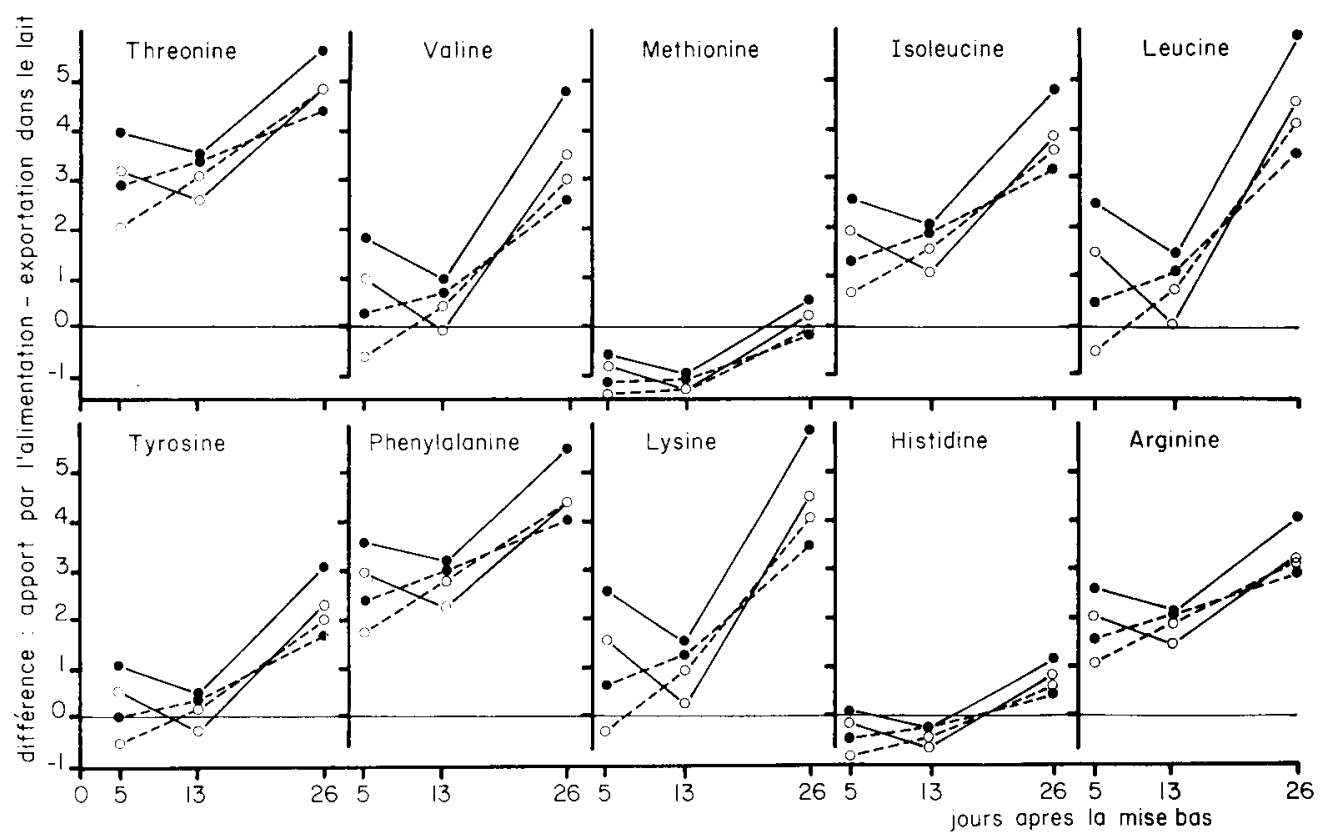

FIG. 5. - Différence entre les quantités journalières (g) d'acides aminés indispensables ef semi-indispensables apportées par l'alimentation (1) et celles exportées dans le lait $\left({ }^{2}\right) . \bullet-\longrightarrow$ lot GHD o—— lot MHD •--..-• lot GBD o-..... lot MBD.

Troisième et quatrième semaine. - A la 4 e semaine de la lactation, les quantités d'acides aminés indispensables et semi-indispensables (excepté la méthionine) exportées journellement dans le lait, sont inférieures à celles apportées par l'alimentation (fig. 5). Le fait que les teneurs de la plupart des acides aminés indispensables et semiindispensables libres ne varient que peu, indique une réduction du catabolisme protéique.

b) Influence de la sous-alimentation énergétique pendant la fin de la gestation ef de l'absence de réserves corporelles suffisantes.

La sous-alimentation énergétique pendant la fin de la gestation aussi bien que l'absence de réserves corporelles suffisantes ont des conséquences pendant les 2 pre-

(1) Estimées à partir de la quantité de protéines digestibles dans l'intestin (PDI) (Jarrige, Journet ef Vérité, 1978) et de la composition en acides aminés des contenus de duodénum de chèvre (Champredon, 1972).

${ }^{(2)}$ Calculées à partir des quantités de lait sécrétées (Tissier, communication personnelle) (contenant 49,7 p. 1000 de matières azotées) et de la composition en acides aminés des matières azotées du laił de brebis. 
mières semaines de la lactation : nette augmentation de la production laitière ef légère diminution de l'ingestion (Tissier, communication personnelle) (łabl. 2). Ceci provoque un accroissement du déficit en glucose et en acides aminés indispensables et semi-indispensables (fig. 5).

Les augmentations de la glycémie et des teneurs sanguines en glutamine + asparagine libres chez les animaux qui ont été soumis à une restriction énergétique sont sans doute dues respectivement à une augmentation de la synthèse de glucose à partir de l'acide propionique et du transport d'ammoniaque du rumen sous la forme de glutamine, ce qui serait la conséquence de fermentations plus importantes dans le rumen dont le volume a moins diminué au cours de la fin de la gestation. Les augmentations des teneurs en acide aspartique et sérine libres peuvent traduire une baisse de la synthèse de glucose à partir de ces composés.

Les baisses des teneurs sanguines en acide glutamique libre chez les animaux qui n'ont pas de réserves corporelles suffisantes, traduisent un accroissement du catabolisme et de l'utilisation de cet acide aminé pour la synthèse de glucose. Les augmentations des teneurs de certains acides aminés indispensables libres peuvent s'expliquer soit par un accroissement du catabolisme protéique, soit par une augmentation de l'apport d'acides aminés par le tube digestif à la suite d'une élévation de la synthèse de protéines microbiennes dans le rumen. Elles sont sans doute la cause de la stimulation de la production laitière puisque Champredon ef al. (1977) ont montré que l'augmentation de l'apport d'acides aminés dans le sang, à la suite de l'ingestion de tourteaux formolés, augmente la quantité de lait sécrétée chez la vache forte productrice de lait.

Aussi bien dans le cas de l'influence de la sous-alimentation énergétique pendant la fin de la gestation, que de celle de l'absence de réserves corporelles suffisantes, les différences observées sont dues vraisemblablement à des différences de volume de rumen.

\section{Conclusion.}

Pendant la fin de la gestation, on constate de faibles glycémies à la suite de l'utilisation importante de glucose par l'utérus. La sous-alimentation énergétique pendant les 7 dernières semaines de la gestation accroît le déficit en glucose puisque l'élévation de la néoglucogenèse à partir de l'alanine ne compense pas le ralentissement de la néoglucogenèse à partir de l'acide propionique ; de plus, elle accroît le catabolisme er réduit l'apport par l'intestin de certains acides aminés indispensables et semiindispensables (tyrosine, phénylalanine). L'absence de réserves corporelles suffisantes est associée à une réduction du déficit en glucose. A l'approche de la mise bas, l'utilisation du glucose par les tissus maternels est sans doute ralentie, de même que le catabolisme des acides aminés et l'incorporation de ces derniers dans les protéines.

Pendant les deux premières semaines de la lactation, le déficit en glucose est moins intense que pendant la fin de la gestation. Ceci est particulièrement net chez les animaux soumis à une sous-alimentation énergétique pendant la fin de la gestation ; chez ces derniers, l'activité fermentaire dans le rumen semble accrue. L'exportation importante d'acides aminés indispensables et semi-indispensables n'est assurée 
qu'au prix d'une mobilisation intense des protéines corporelles; de plus, l'utilisation de ces derniers pour la synthèse des protéines est sans doute limitée à la suite de la forte carence en méthionine. L'absence de réserves corporelles suffisantes accroît l'apport des acides aminés indispensables et semi-indispensables dans le sang.

Reçu en mars 1978.

Accepté en septembre 1978.

\section{Références}

ARNAL M., FAUCONNEAU G., PECH R., 1972. Synthèses protéiques in vivo dans divers tissus du rat en croissance soumis à une réduction de l'apport énergétique de la ration. Ann. Biol. anim. Bioch. Biophys., 12, 91-108.

BAILE C. A., FORBES J. M., 1974. Control of feed intake and regulation of energy balance in ruminants. Physiol. Rev., 54, 160-214.

BARGELOH J. F., HIBBS J. W., CONRAD H. R., 1975. Effect of prepartal hormone administration on feed intake and mineral metabolism in cows. J. Dairy Sci., 58, 1701-1707.

BASSETT J. M., OXBORROW T. J., SMITH I. D., THORBURN G. D., 1969. The concentration of progesterone in the peripheral plasma of the pregnant ewe. J. Endocr., 45, 449-457.

BICKERSTAFFE R., ANNISON E. F., LINZELL J. L., 1974. The metabolism of glucose, acetate, lipids and amino acids in lactating dairy cow. J. ogric. Sci. Camb., 82, 71-85.

BLOM A. K., HOVE K., NEDKVITNE J. J., 1976. Plasma insulin and growth hormone concentrations in pregnant sheep. II- post absorptive levels in mid and late pregnancy. Acta endocr., 82, 553-560.

BROCKMAN R. P., BERGMAN E. N., 1975. Effect of glucagon on plasma alanine and glutamine metabolism and hepatic gluconeogenesis in sheep. Am. J. Physiol., 228, 1627-1633.

BROCKMAN R. P., BERGMAN E. N., JOO P. K., MANNS J. G., 1975. Effects of glucagon and insulin on net hepatic metabolism of glucose precursors in sheep. Am. J. Physiol., 229, $1344-1350$.

BROSTER W. H., 1973. Protein-energy interrelationships in growth and lactation of cattle and sheep. Proc. Nutr. Soc., 32, 115-122.

CHAMPREDON C., 1972. Utilisation de l'aminoacidémie libre comme mesure de la satisfaction du besoin en acides aminés des chèvres laitières. Ełude de quelques facteurs. Thèse Doct. Spéc. (Physiol.), Clermont-Ferrand.

CHAMPREDON C., PION R., 1972. Evolution de l'aminoacidémie libre de chèvres au début de la lactation. C. R. Soc. Biol., 166, 378-381.

CHAMPREDON C., REMOND B., PION R., 1977. Influence d'une sous-alimentation énergétique et azotée sur l'aminoacidémie libre de vaches laitières en début de lactation. $C$. $R$. Soc. Biol., 171, 60-66.

CHAMPREDON C., VÉRITÉ R., PRUGNAUD J., PION R., 1977. Utilisation des tourteaux traités au formol par les vaches laitières. III - Influence sur l'amino-acidémie libre de la formolation des tourteaux, du niveau d'apport azoté et de la nature de l'azote alimentaire. Ann. Zootech., 26, 513-522.

FELIG P., 1973. The glucose-alanine cycle. Metabolism, 22, 179-207.

FORD E. J. H., REILLY P. E. B., 1970. The utilization of free amino acid and glucose carbon by sheep pregnant with twins. Res. Vet. Sci., 11, 575-579.

FULKS R. M., LI J. B., GOLBERG A. L., 1975. Effect of insulin, glucose, and amino acids on protein turnover in rat diaphragm. J. biol. Chem., 250, 290-298.

GRIZARD J., PRUGNAUD J., ARNAL M., PION R., 1975. Effet de l'insuline sur la composition corporelle et les teneurs en acides aminés libres du sang, du foie et du muscle du rat en croissance soumis à une restriction énergétique. Ann. Biol. anim. Bioch. Biophys., 15, 569-582.

GRIZARD J., TISSIER M., THERIEZ M., PION R., 1979. Variations de l'insulinémie chez la brebis en fin de gestation et début de lactation. Influence de l'état nutritionnel en fin de gestation. Ann. Biol. anim. Bioch. Biophys., 19, 73-78. 
GUADA J. A., ROBINSON J. J., FRASER C., 1976. The effect of a reduction in food infake during late pregnancy on nitrogen metabolism in ewes. J. agric. Sci. Camb., 86, 111-116.

HOVE K., BLOM A. K., 1976. Plasma insulin and growth hormone concentrations in pregnant sheep. I - Diurnal variations in mid and late pregnancy. Acta. endocr., 82, 544-552.

JARRIGE R., JOURNET M., VÉRITÉ R., 1978. Azołe, 89-128. In Alimentation des ruminants, Ed. INRA Publications (Route de Saint-Cyr), 78000 Versailles.

KOPROWSKI J. A., TUCKER H. A., 1973. Bovine serum growth hormone, corticoïds and insulin during lactation. Endocrinology, 93, 645-651.

KRONFELD D. S., 1972. Ketocis in pregnant sheep and lactating cow. Aust. veter. J., 48, 680-686.

MACKIE W. S., CAMPBELL R. M., 1972. Effects of pregnancy and lactation on the activities of some gluconeogenic and urea-cycle enzymes in sheep liver. J. agric. Sci. Camb., 79, 423-429.

MOORE S., SPACKMAN D. H., STEIN W. H., 1958. Chromatography of amino acids on sulfonated polystyrene resins. Analyt. Chem., 30, 1185-1190.

OFFER N. W., TAS M. V., AXFORD R. F. E., EVANS R. A., 1975. The effect of glucose infusion on the plasma free amino acids in sheep. Br.J. Nutr., 34, 375-382.

PAWLAK M., PION R., 1968. Influence de la supplémentation des protéines de blé par des doses croissantes de lysine sur la teneur en acides aminés libres du sang et du muscle du rat en croissance. Ann. Biol. anim. Bioch. Biophys., 8, 517-530.

PION R., 1976. Dietary effects and amino acids in tissues, 259-277. In COLE D. J. A., BOORMAN K. N., BUTTERY P. J., LEWIS D., NEALE R. J., SWAN H., Protein metabolism and nutrition. Butterworths, Londres.

PRIOR R. L., CHRISTENSON R. K., 1976. Influence of diefary energy during gestation on lambing performance and glucose metabolism in Finn-cross ewes. J. anim. Sci., 43, 1114-1124.

PRIOR R. L., CHRISTENSON R. K., 1977. Gluconeogenesis from alanine in vivo by the ovine fœetus and lamb. Am. J. Physiol., 233, E462-E468.

RÉRAT A., DESMOULIN B., 1970. Influence d'une restriction alimentaire, énergétique et azotée sur la croissance et la composition corporelle du rat blanc. Ann. Zootech., 19, 103-115.

SNEDECOR G. W., COCHRAN W. G., 1971. Méthodes statistiques. A.C.T.A. ed., Paris.

SPIRES H. R., CLARK J. H., DERRIG R. G., DAVIS C. L., 1975. Milk production and nitrogen utilization in response to postruminal infusion of sodium caseinate in lactating cows. J. Nutr., 105, 1111-1121.

TERQUI M., DELOUIS C., 1975. Les œstrogènes au cours de la gestation ef la parturítion chez la brebis, 332-341. In INRA ITOVIC, Journées Recherches Ovines, Ed. S.P.E.O.C., Paris.

TISSIER M., BRELURUT A., 1976. Diagnostic du nombre de fætus chez la brebis par radiographie aux rayons $X$ avec un appareil portable de faible puissance. Ann. Zoofech., 25, 411-415.

TISSIER M., THERIEZ M., 1978. Ovins, 403-448. In Alimentation des ruminants, Ed. INRA Publications (Route de Saint Cyr), 78000 Versailles.

TISSIER M., THERIEZ M., MOLENAT G., 1975. Evolution des quantités d'aliment ingérées par les brebis à la fin de la gestation et au début de la lactation. Incidence sur les performances I - Ełude de deux rations à base de foin de qualité différente. Ann. Zootech., 24, 711-727.

VERMOREL M., 1978. Utilisation énergétique des produits terminaux de la digestion, 47-88. In Alimentation des ruminants. Ed. INRA Publications (Route de Saint-Cyr), 78000 Versailles.

WOOL I. G., 1972. Insulin and the regulation of protein synthesis in muscle. Proc. Nutr. Soc., 31, 185-191.

YOUNG J. W., 1976. Gluconeogenesis in cattle : significance and methodology. J. Dairy Sci., 60, 1-15. 